Department of Health. Health of the nation. London: HMSO, 1992.

Social Exclusion Unit. Teenage pregnancy. London: Stationery Office, 1999

Scottish Office. Towards a healthier Scotland. Edinburgh: Stationery Office, 1999

4 Diamond I, Clements S, Stone N, Ingham R. Spatial variation in teenage conceptions in south and west England. J R Stat Soc Ser A 1999;162:27389.

5 Churchill D, Allen J, Pringle M, Hippisley-Cox J, Ebdon D, Macpherson $\mathrm{M}$, et al. Consultation patterns and provision of contraception in general practice before teenage pregnancy: case-control study. BMJ 2000;321:486-9.

6 Smith T. Influence of socioeconomic factors on attaining targets for reducing teenage pregnancies. BMJ 1993;306:1232-5.

7 ISD. Teenage pregnancy in Scotland: a fifteen year review, 1983-97. Edinburgh: Common Services Agency for the Scottish Health Service, Information and Statistics Division, 1998 .
8 Carstairs V, Morris R. Deprivation and health in Scotland. Aberdeen: Aberdeen University Press, 1991.

9 Coory M, Gibberd R. New measures for reporting the magnitude of small-area variation in rates. Stat Med 1998;17:2625-34

10 Information and Statistics Division. Scottish health statistics 1984. Edinburgh: HMSO, 1984.

11 Information and Statistics Division. Scottish health statistics 1995. Edinburgh: HMSO, 1995.

12 Rigsby D, Macones G, Driscoll D. Risk factors for rapid repeat pregnancy among adolescent mothers: a review of the literature. J Pediatr Adoles Gynecol 1998;11:115-26.

13 Stevens-Simon C, Kelly L, Singer D, Cox A, DuRant R. Why pregnan adolescents say they did not use contraceptives prior to conception. Adolesc Health 1996; 19:48-55.

(Accepted 10 May 2001)

\title{
"They're doing people a service"-qualitative study of smoking, smuggling, and social deprivation
}

Susan Wiltshire, Angus Bancroft, Amanda Amos, Odette Parry

\begin{abstract}
Objectives To examine the behaviour and attitudes related to smoking and contraband tobacco products among smokers in two socially deprived areas. Design Cross sectional study with qualitative semistructured interviews, augmented by smokers' day grid.

Setting Two areas of socioeconomic deprivation in Edinburgh.

Participants 50 male and 50 female smokers aged 25-40 years randomly selected from general practitioners' lists from two health centres, each located in an area of deprivation.

Results Most smokers wanted to quit but felt unable to because of the importance of smoking in their daily routine and their addiction to nicotine. Strategies for maintaining consumption levels in the face of increasing cigarette prices and low income included purchasing contraband cigarettes and tobacco. Vendors were contacted through social networks, family, and friends as well as common knowledge of people and places, particularly pubs where contraband was available. Most users of contraband considered that smugglers were providing a valuable service. Purchasing contraband tobacco was viewed as rational in the face of material hardship. Many smokers criticised the government for its high tobacco taxation and the lack of local services to help them to stop smoking.

Conclusions Smokers in deprived areas perceive a lack of support to help them to stop smoking. Cigarette and tobacco smuggling is therefore viewed positively by low income smokers as a way of dealing with the increasing cost of cigarettes. Smokers in areas of deprivation may thus show little support for tackling smuggling until more action is taken to deal with the material and personal factors that make it difficult for them to quit.
\end{abstract}

\section{Introduction}

Smoking is strongly associated with social disadvantage and is an important contributor to inequalities in health. ${ }^{1-3}$ The greater an individual's level of disadvantage (as measured, for example, by occupation, income, education, housing tenure) the more likely they are to start smoking and the less likely they are to stop. ${ }^{45}$ The government's white papers on tobacco and public health have identified reduction in smoking among low income groups as a priority and a key element of its strategy for tackling health inequalities. ${ }^{2}{ }^{67}$ Cessation services are being targeted at low income smokers and those who live in areas of deprivation. However, there is increasing concern that the impact of these services and the government's tobacco control strategy may be being undermined by the increasing availability of cheap, smuggled cigarettes and tobacco. ${ }^{8}$

The 1990s saw a massive increase in the smuggling of tobacco and cigarettes into the United Kingdom. It is estimated that currently a quarter to a third of cigarettes smoked in the United Kingdom, worth $£ 2500$ million in lost revenue during 1999, are smuggled or contraband. ${ }^{9}$ There is clear evidence that tobacco companies are complicit in smuggling. ${ }^{8-11}$ Tobacco companies use concerns about smuggling, and the resulting lost tax revenue, to exert political pressure on the government to lower tobacco taxes. Evidence from other countries shows that lowering taxes neither decreases smuggling nor reduces overall tobacco consumption. ${ }^{10}$

However, we know little about how smokers in areas of deprivation view the issue of smuggled or contraband cigarettes and tobacco, how this relates to their own smoking behaviour, and the implications for policies and action on this issue. In this paper, which draws on a wider study of smoking in areas of deprivation, we have focused on the strategies that smokers living in such areas use to deal with the financial costs of smoking. Specifically, we considered the role of cigarette and tobacco smuggling: sources, availability, respondents' rationale for purchasing contraband, and the impact of cheaper tobacco products on smoking behaviour.

\section{Methods}

Participants and setting-We used data from a two year qualitative study of smokers living in two areas of Edin-
Public Health

Sciences,

Department of

Community Health

Sciences, University

of Edinburgh

Medical School,

Edinburgh

EH8 9AG

Susan Wiltshire

research fellow

Angus Bancroft

lecturer

Amanda Amos

senior lecturer

Research Unit in

Health, Behaviour

and Change,

Department of

Community Health

Sciences, University

of Edinburgh

Medical School

Odette Parry

senior research fellow

Correspondence to:

A Amos

amanda.amos@

ed.ac.uk

BMJ 2001;323:203-7 
burgh that are defined as socially deprived by using deprivation category (DEPCAT) scores. ${ }^{12}$ The sample was randomly selected from general practitioners' records of smokers at two health centres, each located in one of the two areas. General practitioners sent out a letter with information about the study and an opt out form. We contacted respondents who did not opt out to arrange an interview. Of the 167 smokers with whom we made contact, we interviewed 50 men and 50 women aged 25-40 years.

Interviews-Interviews, conducted from October 1999 to July 2000, were about one hour long and took place in respondents' homes. Respondents selected a recent day to describe in detail their "typical" smoking behaviour, and these data were entered on a day grid. ${ }^{13}$ The grid recorded structured data on daily experiences and events across different domains (home, work, leisure, food, family, and friends) and cigarette use. We also used a checklist to guide discussion on current daily consumption; reasons for smoking; environmental, social and other influences on smoking; and previous attempts to stop and future intentions to stop.

Analysis-We transcribed the interviews into NUD*IST, with the grids reproduced in Excel. We read transcripts in conjunction with the grids and produced profile of "typical" daily smoking contextualised for each respondent. These profiles enabled smoking behaviour to be placed in context against routine events and circumstances across the day. The transcribed data were analysed by all the authors. Regular discussions were held to achieve consensus on emerging themes from the descriptive to the analytical stages. We organised coding using NUD*IST, indexing data in terms of similarity and contrast of content. Finally, we compared and contrasted the conditions and circumstances in which smokers articulated these different themes with extracts from the transcripts used to illustrate particular points.

\section{Results}

Most respondents lived in council or housing association accommodation. Less than half were in full time employment (table) and many of these worked irregular hours, such as variable shifts. Most smoked around 20 cigarettes a day, with women smoking slightly less than men (table). While most respondents stated that they wanted to stop smoking, few could contemplate abstinence for a day or longer as smoking was an important part of their daily routine and iden-

Employment status and daily cigarette consumption of 100 participants by sex

\begin{tabular}{lcc} 
& Men $\mathbf{( n = 5 0 )}$ & $\begin{array}{c}\text { Women } \\
(\mathbf{n}=\mathbf{5 0})\end{array}$ \\
\hline Employment: & 27 & \\
\hline Full time & 2 & 12 \\
\hline Part time & 17 & 14 \\
\hline Not employed & 4 & 24 \\
\hline Missing & & 0 \\
\hline Cigarette consumption: & 12 & 6 \\
\hline $1-9$ & 19 & 29 \\
\hline $10-19$ & 9 & 11 \\
\hline $20-29$ & 6 & 3 \\
\hline$\geq 30$ & 4 & 1
\end{tabular}

Box 1 Strategies to maintain smoking consumption

- Purchasing cheaper brands of cigarettes

- Switching to home rolled cigarettes

- Cross border shopping

- Buying contraband products

- In a small minority of cases, respondents tried to reduce their cigarette consumption to reduce costs

\section{Box 2 Awareness of contraband}

If I can get them cheap then I do, because I grudge going in and paying four pound odd for a packet of cigarettes (F21)

Basically everybody does it, we used to get the contraband stuff. I mean roll-ups, you're four quid, and I was only spending sixteen pound in a month (M22)

A hundred and nine pound, that's what I get a week, but I still manage to have my two hundred cigarettes, cause I get them on the cheap (F1)

If you smoke in most pubs, you can get it. If it costs eight pound in the shops, you'll get it for four. But anybody ... would go to the pub and pay four ... If you could get food for ten pence instead of twenty pence, you would (M23)

tity. Indeed, many respondents claimed to be addicted, most notably to cigarettes smoked at particular times of the day, such as first thing in the morning (A Bancroft, personal communication, 2001).

Respondents discussed the impact of smoking on their finances. Although they often commented that money for smoking would be found somehow, various conscious strategies were adopted to maintain smoking in difficult circumstances (box 1).

\section{Contraband tobacco products}

Several respondents admitted buying contraband, with most having some knowledge of contraband, such as where to buy products, prices, available brands, and countries of origin (box 2). This was often referred to as buying "on the cheap." If respondents thought they could not afford shop prices, then it was reasonable to access a seller with cheaper products.

\section{Access to contraband}

There were several different sources of contraband, with the most popular being public houses (box 3). One man (M19) spoke about the availability of cheap tobacco in city pubs and the relative ease of access. Other respondents took advantage of personal foreign holidays, or those of family or friends, with their cross border tax differentials. A minority of respondents were less specific about where their tobacco products came from. Commodities could be accessed through common knowledge-that is, they might hear of people who were able to get them. As one woman confided: "it just depends, some people you know, can get them" (F21). Other respondents spoke of vendors calling at their houses, and one mentioned contraband being available in a local shop (box 3).

Some respondents bought contraband loose tobacco for rolling cigarettes as it was cheaper and more regularly available than manufactured cigarettes: 


\section{Box 3 Sources of contraband}

Pubs

They just go away and get you fags ... [They say] come down on such and such a day and they'll be here for you. When I went down to Leith one night a guy was trying to sell me tobacco for five packs a tenner (M19)

Holidays

My brother's just back from Turkey and he's brought cigarettes home ... [I smoke] whatever he's got ...

There are so many people doing this on the cheap (F20)

Door to door

There's that many people want to sell you them. You don't have to go over, they'll come to your door with them (M14)

Shops

I can get it, like a half ounce for a pound, up at the corner shop, it's the cheapest tobacco there .... a mixture of all different tobaccos all mixed in, but it's not too bad (M10)

"I buy the stuff that's been duty free, the stuff that's coming from abroad. I'm only spending about a pound a week ... It's easier to get tobacco, you can get tobacco on a regular basis. You get some cigarettes. Some weeks somebody might not have any and so if you're smoking tips then he's going to let you down" (M10).

While national data indicate that smoking home rolled cigarettes is almost exclusively a male habit, ${ }^{7}$ several respondents indicated that the behaviour may be increasing among women living in their area. One man (M7) said "a lot of women ... smoke roll-ups as well ... perfectly normal sort of women."

\section{Attitudes to smuggled tobacco products and government taxation}

Respondents viewed smuggling as a reasonable response to the perceived high price of cigarettes, due mainly to tax: "I mean the thing is I just struggle even more to get the money for cigarettes, I think .... And of course there's all these illegal supplies being brought in from France, people will just go and buy them I would imagine" (F20).

Most considered tax on cigarettes as excessive, especially compared with the price of cigarettes abroad. For example, one woman (F50) was scathing of current tax levels: "If you can get them for two pound a packet abroad and it's costing you over four pound here, that's at least half is tax and probably more."

Some respondents believed that high cigarette taxation encouraged smuggling (box 4). Many respondents thought that higher prices would simply make them worse off. Finding cigarette money would remain a priority, as they were addicted and unable to quit (box 4). Raising prices was perceived as punitive, punishing the smoker and his or her family. Moreover, several people said that the government was doing little to support attempts to stop because of a reluctance to redirect or lose out on tax revenue (box 4). Many respondents said that, regardless of the price of legal products, they would continue to use contraband. However, if taxes were raised further, family expenditure would have to be adjusted.

Nearly all respondents expressed dissatisfaction with the price of legal tobacco products. It was thought to be unjust and directed against people on low incomes. Participants were asked directly what influence the increasing price of cigarettes resulting from the government's taxation policy had on their smoking. Only a few intimated that higher prices might act as an incentive to reduce smoking or that cheaper cigarettes encourage higher consumption: "Maybe if the price of cigarettes went up dramatically even more, I maybe would stop smoking ... I only buy ten ... If cigarettes were cheaper I would buy twenty, because when I go on holiday they're cheaper and I buy a lot" (F6).

One man (M14) summarised the positive attitude to smuggling held by many respondents: "to me, they're doing you a favour ... They're doing people a service." A few respondents, however, expressed reservations about smoking contraband from the fear of its illegal nature to effects on health and the taste of some of the products: "I'd rather pay more money for them ... because the ones they're selling, I'm frightened in case I get them harsh ones again, because that's what actually started my throat... I was always coughing up" (M13). Another man spoke about counterfeit products: "The cheap fags came over for a while, we were buying them but they had a ring around them. They were classed as Regal but they weren't Regal ... They were giving us sore throats" (M19).

\section{Discussion}

We have shown that an easily accessible cigarette and tobacco smuggling network operates in at least two deprived areas in Edinburgh and that smokers may access this in various ways. The primary rationale for doing so is that products acquired in this way decrease

\section{Box 4 Attitudes to tobacco taxation and price}

Encouraging smuggling

If they don't want this sort of society then they shouldn't have gone about their business the way they did ... It's obvious if people can find a way to get cheaper fags they'll do it, you know, and if the government's price wasn't that high, it wouldn't be such a problem (M43).

\section{Encouraging smoking}

With the amount of bootleg cigarettes ... it's just encouraging you even more to keep smoking with these people getting a hold of all these cheap cigarettes and tobacco from other countries. So putting the prices up is really not going to make any difference (F21).

\section{Addiction and lack of cessation support}

If you were a drug addict for twenty five years, you'd get help to stop, to come off the drugs, but they don't give you help just now with stopping. It's all revenue for the government, that's the problem. They tell you to stop smoking on the one hand but they throw cigarettes down your throat with the next hand (M22).

I believe the government should be doing more. Instead of putting prices up, which they are doing every budget ... If you're addicted to something, you'll pay whatever it takes to get that item (F14).

\section{Addiction and regressive taxation}

You're paying tax on everything ... and to claim that tax off the smokers is quite bad ... There's people out there that are on crap money with the dole, hooked on fags. They've got to buy fags and they end up there's nothing left for them or their kids' dinner or that, because it's all got to go on the fags ... There's enough smokers that they could make a healthy whack, they don't need to be greedy .... and it's not all going back in to public spending (M17). Well I mean considering the fact that all the money the government's... putting on fags, if that money was solely to go back in to the health care area, fair do's, but you know it doesn't (M11). 
the costs of smoking for those living on scarce financial resources. Another motivating factor hinges on the notion of resistance. Respondents expressed grievances against the government for clawing back what they viewed as an excessive and regressive tax on tobacco products and for their failure to redirect this income visibly towards those in need. In particular, many highlighted the lack of support available to help them deal with what they thought was, given their difficult circumstances, an intractable addiction to tobacco. There was a strong feeling that the government was exploiting poorer people through regressive tobacco taxation. Use of contraband was one means of challenging this perceived injustice. No respondent mentioned the major role of tobacco companies in smuggling. Rather they viewed smugglers as people similar to themselves who provided a welcome service for smokers in their area.

The study had several limitations. The sample was small and was not intended to provide statistically representative views of smokers in these areas. Given the illegal nature of purchasing contraband, respondents were not pressed to state explicitly whether they had purchased contraband and thus many more may have been involved than are reported here. An increasing number of smokers in these areas may be accessing contraband as participants interviewed towards the end of the study were more willing to talk about this than those interviewed earlier. However, despite these limitations it seems that, given the dual pressures of nicotine addiction and surviving on low incomes, many smokers will be predisposed to buy contraband where this is available or exploit cross border tax differentials, or both.

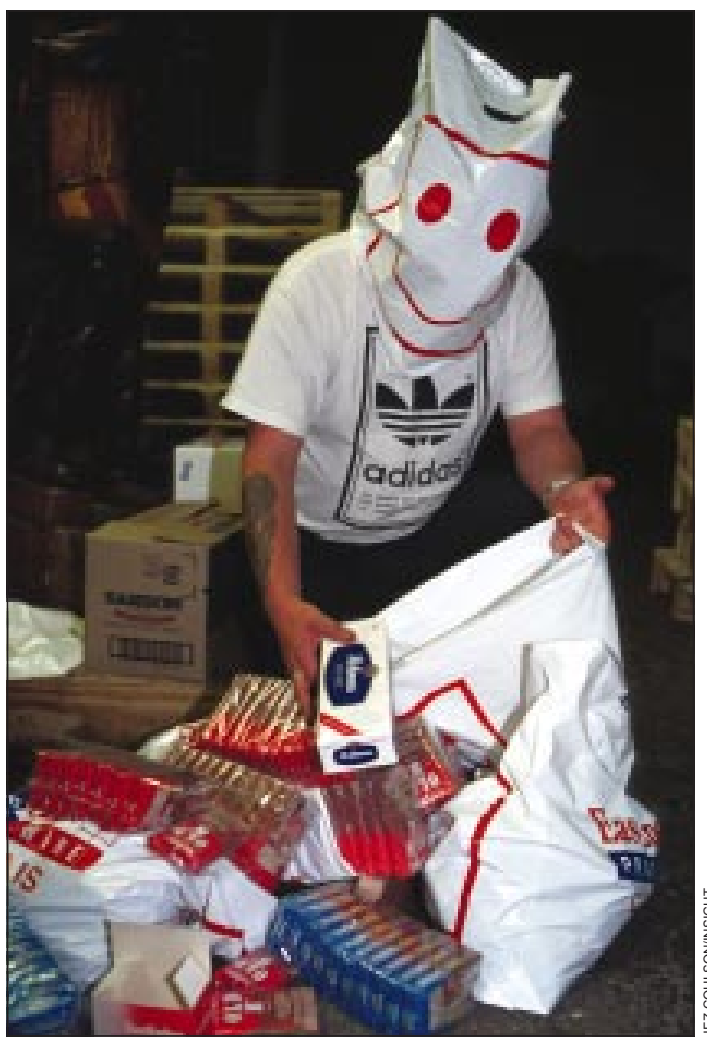

An estimated quarter to a third of cigarettes smoked in the UK are smuggled or contraband, costing around $£ 2500$ million in lost revenue in 1999

\section{What is already known on this topic}

Areas of deprivation have the highest rates of smoking and lowest levels of cessation

Around $25-30 \%$ of cigarettes consumed in the United Kingdom are contraband

We know little about the attitudes of smokers in these areas to smuggled cigarettes or whether and how they access them

\section{What this study adds}

In such areas the easy availability of cheap tobacco products through contraband networks works against many smokers' desire to quit

Given the perceived lack of support to help them to stop smoking, this smuggling network is viewed positively by low income smokers as a way of dealing with the increasing cost of cigarettes

Smokers in areas of deprivation may thus show little support for tackling smuggling until more action is taken to address the material and personal factors that make it difficult for them to quit

Smuggling stimulates and maintains consumption through its low prices and acts to nullify one of the major planks of the government's tobacco control strategy-regular, above inflation, increases in tobacco taxation. The government has already taken action to reduce smuggling, but more needs to be done. This could include ensuring that details of the wholesaler, countries of origin, and destination are clearly marked on packets. ${ }^{14}$ However, this study suggests that smokers in areas of deprivation may show little support for tackling smuggling until more action is taken to deal with the wider material and personal factors that make it so difficult for them to quit. Many smokers would support action by the government to deal with the regressive nature of tobacco taxation. This would include addressing poverty and social inequalities and providing more readily accessible and acceptable support for smoking cessation in disadvantaged communities. ${ }^{15}$ A proportion of tobacco taxation could be allocated to this end. At the very least it is essential that the cessation services that have started to emerge with funding from the white paper are given long term sustainable funding and are expanded to become more accessible to disadvantaged smokers across Britain. ${ }^{16}$

We thank the participants and the general practitioners who participated in this study and Ruth Scott for her secretarial support. The views expressed in this paper are those of the authors and do not necessarily reflect the views of the funding body.

Contributors: SW undertook the primary data analysis and drafting of the paper. AA and OP had the original idea for the study, supervised the project, and were involved in designing the interview schedule, identification of coding themes, discussion of data analysis, and editing of the paper. $\mathrm{AB}$ was involved in designing the interview schedule, undertook all the interviews and most of the data coding, and commented on drafts of the paper. AA and OP are guarantors.

Funding: Chief Scientist Office, Scottish Executive Health Department.

Competing interests: None declared. 
1 Bridgwood A, Lilly R, Thomas M, Bacon J, Sykes W, Morris S. Living in Britain 1998. London: Stationery Office, 2000

2 Secretary of State for Scotland. Towards a healthier Scotland. Edinburgh: Stationery Office, 1999

3 Dorset R, Marsh A. The health trap: poverty, smoking and lone parenthood. London: Policy Studies Institute, 1998.

Graham H, Der G. Patterns and predictors of smoking cessation among British women. Health Promot Internation 1999;14:231-9.

5 Graham H, Der G. Influences on women's smoking status: the contribution of socioeconomic status in adolescence and adulthood. Eur J Public Health 1999;9:137-41.

6 Secretary of State for Health. Smoking kills. London: Stationery Office, 1999.

7 Secretary of State for Health. Saving lives: our healthier nation. London: Stationery Office, 1999 .

8 Joossens L. Smuggling and cross-border shopping of tobacco products in the European Union. London: Health Education Authority, 1999.

9 Rowell A, Bates C. Tobacco smuggling in the UK. London: Action on Smoking and Health, 2000.

10 Joossens L, Raw M. Cigarette smuggling in Europe: who really benefits? Tob Control 1998;7:66-71.
11 Jha P, Chaloupka FJ. The economics of global tobacco control. BMJ 2000;321:358-61

12 Carstairs V, Morris R. Deprivation and health in Scotland. Health Bull Edinb 1990;48:162-5.

13 Parry O, Thomson C, Fowkes FG. Life course data collection: qualitative interviewing using the life grid. Sociological Research Online 1999;4(2) on www.socresonline.org.uk/socresonline/4/2/parry.html (accessed 5 July 2001).

14 Joossens L, Raw M. How can cigarette smuggling be reduced? BMJ 2000;321:947-50.

15 Gaunt-Richardson P, Amos A, Howie G, McKie L, Moore M. Women, low income and smoking-breaking down the barriers. Edinburgh: Action on Smoking and Health Scotland/Health Education Board for Scotland, 1999.

16 Crosier A. A rapid mapping study of smoking projects and services targeted at people living on low income and/or minority ethnic groups. London: Health Development Agency, 2001.

(Accepted 29 June 2001)

\title{
Mortality in children registered in the Finnish child welfare registry: population based study
}

\author{
Mirjam Kalland, Tiina H Pensola, Jouni Meriläinen, Jari Sinkkonen
}

Studies have shown inverse associations between childhood social class and mortality, ${ }^{1}$ and others have shown higher mortality in children in care. ${ }^{23}$ However, to our knowledge, only one study has investigated mortality in children in care with results specific to sex and cause of death. ${ }^{3}$ Mortality in that study was higher than expected among boys, although mortality related to age at the time of death was not reported. ${ }^{3}$

In Finland, children are cared for within the child protection system up to the age of 18 . Our specific interest lies in whether mortality before age 18 in children in care is higher than expected on the basis of figures for the general population, reflecting failure in the child protection system, or whether mortality is increased from age 18, reflecting difficulties in adapting to independent living.

\section{Methods and results}

The basic data source was the Finnish child welfare registry. The data were completed by individual linkage with the Finnish cause of death registry, using the personal identification number of each child. The study covered all children in Finland who were taken into care between 1 January 1991 and 31 December 1997 $(\mathrm{n}=13$ 371). One per cent (133) could not be linked to the cause of death registry owing to errors in the personal identification number. All subjects were born between 1 January 1973 and 31 December 1997 and followed up until 31 December 1999 or, if earlier, their 25th birthday or, if earlier, their death. During the study period 106 individuals (32 females and 74 males) died. Mortality ratios standardised for age were used to compare the mortality of children in the cohort (girls and boys separately) with that of the general population of the same age in Finland.

In this cohort, both sexes had higher mortality than would have been expected on the basis of general population figures (table). We also compared the mortality of the cohort with that of Finnish people aged
5-24 from the manual class. ${ }^{4}$ The mortality ratio for females was 282 (95\% confidence interval 189 to 405$)$, and that for males was 218 (169 to 275), indicating that mortality was higher in comparison with this socially disadvantaged group.

The higher mortality of the cohort is related to deaths caused by substance misuse, accidents, and suicide. Six females and 29 males aged 15-24 years committed suicide, with mortality ratios of 353 (130 to 768) and 242 (162 to 348) respectively. Deaths related to alcohol and drug misuse also occurred at a higher rate than expected; the mortality ratio for females was 841 (385 to 1597), and that for males was 420 (291 to 587).

Fourteen girls and 24 boys died before the age of 18, of whom seven girls and 11 boys died of illness (four girls and seven boys aged <11). This can be attributed to an increase in acute and chronic health conditions and developmental delays among children in foster care. ${ }^{5}$

\section{Comment}

We found that both females and males in the child welfare registry cohort had excess mortality in comparison with the general population or the manual class. Excess mortality of males was not higher than that of females (see table). The belief that girls are more resilient to environmental factors than boys was thus not

Save the Children, Finland, PO Box 177 Lapinrinne 2 , FIN-00180 Helsinki, Finland Mirjam Kalland researcher Jari Sinkkonen senior research officer

Population Research Unit, Department of Sociology, PO Box 18 , FIN-00014 University of Helsinki, Finland Tiina H Pensola researcher

National Research and Development Center for Welfare and Health, Siltasaarenkatu 18 Box 220, FIN-00531 Helsinki, Finland Jouni Meriläinen planning officer

Correspondence to: M Kalland mirjam.kalland@ pela.fi

BMJ 2001;323:207-8

Mortality ratios standardised for age* of Finnish people aged 1-24 in the child protection system in 1991-9, and the number of deaths and person years

\begin{tabular}{lccccc} 
& \multicolumn{2}{c}{ Females } & & \multicolumn{2}{c}{ Males } \\
\cline { 2 - 3 } \cline { 6 - 6 } $\begin{array}{l}\text { Age group } \\
\text { (years) }\end{array}$ & $\begin{array}{c}\text { Mortality ratio } \\
(\mathbf{9 5 \%} \text { CI) }\end{array}$ & $\begin{array}{c}\text { Deaths/ } \\
\text { person years }\end{array}$ & & $\begin{array}{c}\text { Mortality ratio } \\
(\mathbf{9 5 \%} \text { Cl) }\end{array}$ & $\begin{array}{c}\text { Deaths/ } \\
\text { person years }\end{array}$ \\
\hline $1-10$ & $186(51$ to 476$)$ & $4 / 14626$ & & $270(117$ to 532$)$ & $8 / 15079$ \\
\hline $11-17$ & $351(137$ to 524$)$ & $10 / 16961$ & & $201(115$ to 326$)$ & $16 / 19292$ \\
\hline $18-24$ & $441(261$ to 693$)$ & $18 / 11875$ & & $318(236$ to 419$)$ & $50 / 13534$ \\
\hline $1-24$ & $330(226$ to 466$)$ & $32 / 43462$ & & $279(219$ to 350$)$ & $74 / 47905$ \\
\hline
\end{tabular}

*The mortality of Finnish males and females aged 1-24 in 1991-6 is used as a standard. 